\title{
Mechanical Wastewater Facility Challenges in the Canadian Arctic
}

\author{
Ken Johnson ${ }^{1, *}$, Glenn Prosko ${ }^{1}$, David Lycon ${ }^{2}$ \\ ${ }^{1}$ Stantec Consulting Ltd. Edmonton, Alberta, Canada \\ ${ }^{2}$ Stantec Consulting Ltd., Surrey, British Columbia, Canada
}

Copyright $\bigcirc 2017$ by authors, all rights reserved. Authors agree that this article remains permanently open access under the terms of the Creative Commons Attribution License 4.0 International License

\begin{abstract}
The consistent performance of wastewater treatment in the far north of Canada, in general, remains an elusive objective, and a frustration for engineers, communities, senior governments, and regulators. Lagoon systems suffer from performance inconsistencies, and a significant scientific effort has been underway by the Government of Nunavut to study and predict the performance of lagoon systems. It has been pointed out that those systems which are technologically simple, and engineered for sufficient capacity tend to perform well, however lagoon systems are ultimately at the mercy of the natural environment, which is extreme in the far north. Mechanical systems do offer the opportunity to reduce the influence of the natural environment, however a multitude of other factors affect the design, construction, operation and maintenance of mechanical systems in the far north. As an opportunity to mitigate the challenges associated with mechanical wastewater systems, a synopsis of the community mechanical treatment facilities in the north has been compiled. Lessons learned from the challenges with mechanical wastewater systems in the far north have been catalogued as a legacy document to future project stakeholders. This compilation is a first attempt to provide documentation to serve as a reference for improving the development, execution, and operation of future mechanical wastewater treatment projects, where this technical option is deemed appropriate.
\end{abstract}

Keywords Canada, Arctic, Mechanical Wastewater Facility, Challenges

\section{Introduction}

New regulatory requirements for wastewater have been established by the Canadian Council of Ministers of the Environment and the Wastewater Systems Effluent Regulations. Although these regulations have not been adopted by the Government of Nunavut, they are referenced as an objective by the regulatory resources of the Government of Canada. These potential objectives have created a serious concern for the Government of Nunavut and the communities of Nunavut, and communities across the north, regarding the future application of mechanical treatment systems, and the legacy that these systems will impose upon a community.

Wastewater management practices in the Yukon, Northwest Territories and Nunavut Territory have undergone tremendous change over the past 40 years. These changes have been the most profound in the small communities, where the term "honey bucket" remains well known. The transition from the "honey bucket", a bagged collection of wastewater, to pressured water systems has meant that the management of community sewage has changed in principle, from a solid waste to a liquid waste, which is now generated in relatively large volumes. To cope with these large volumes of liquid waste, most northern communities now use pond systems to detain or retain the volume prior to discharge. These pond systems are either natural systems or manmade systems.

Along with the technological transition has come a regulatory change with the development of regulatory requirements for the discharge of effluent from the sewage ponds. Before the creation of Nunavut, the Northwest Territories Water Board had the sole responsibility for dictating the discharge criteria from sewage ponds; the general criteria applied for effluent discharges were 180 $\mathrm{mg} / \mathrm{L}$ for $\mathrm{BOD}_{5}$, and $120 \mathrm{mg} / \mathrm{L}$ for total suspended solids (TSS) [1]. A detention lagoon with a continuous discharge providing around 10 days of hydraulic retention will generally meet this criteria, with the exception of $\mathrm{BOD}_{5}$, which may not be achieved in the winter because of the cold temperatures that adversely impact biological activity.

Most northern communities utilize either sewage detention (ponds with continuous discharge) or sewage retention (ponds with periodic discharge), and overall these systems perform well because of the simple technology. Exceptions to the application of sewage detention or retention have emerged due to site specific conditions that 
generally exclude their application because of topographic conditions, where terrain is too rough for the construction of a lagoon, or land use issues, where proximity to other development restricts the siting of a lagoon.

A significant intervening factor for wastewater management in the far north has been the Wastewater Systems Effluent Regulations, which have been developed under the Fisheries Act, to fulfill a commitment under the Canadian Council of Ministers of the Environment (CCME) Strategy for the establishment of national effluent quality standards. The essence of the "harmonized" wastewater effluent criteria has been to standardize effluence quality targets of $25 \mathrm{mg} / \mathrm{L}$ for cBOD and $25 \mathrm{mg} / \mathrm{L}$ for TSS. Unfortunately, these criteria are generally not appropriate for wastewater lagoon systems in the north, due to the harsh climate, and the seemingly perpetual winter. While only the Yukon has formally adopted these standards, the other territories and the northern regions of Quebec (Nunavik) and Labrador (Nunatsiavut) are attempting to work within the "spirit" of the regulations.

The consistent performance of wastewater treatment in the far north of Canada, in general, remains an elusive objective and a frustration for engineers, communities, senior governments and regulators

\section{Performance of Lagoon Systems}

Detention lagoons provide a continuous discharge, and retention ponds provide a periodic, usually seasonal, discharge. Overall these systems tend to perform well because of the simple technology, although there have been problems with undersized systems, maintenance deficiencies, poor design and construction, and poor operation practices [2].

The performance data on lagoon systems (retention lagoon) in the north is limited, but indicates a $\mathrm{BOD}_{5}$ reduction in the range of 90 to 95 percent $\left(\mathrm{BOD}_{5}\right.$ less than $150 \mathrm{mg} / \mathrm{L}$ and as low as $11 \mathrm{mg} / \mathrm{L}$ ), TSS reduction in the range of 90 to 95 percent (TSS less than $80 \mathrm{mg} / \mathrm{L}$ and as low as $5 \mathrm{mg} / \mathrm{L}$ ) and fecal coliform reduction in the range of 2 to 4 logs (fecal coliforms less than $2 \times 10^{6}$ and as low as $\left.3 \times 10^{1}\right)$. The influent sewage is estimated to be $600 \mathrm{mg} / \mathrm{L}$ BOD, $725 \mathrm{mg} / \mathrm{L} \mathrm{SS}$, and $10^{7}$ coliforms $/ 100 \mathrm{~mL}$ [3].

The capital cost of lagoon systems in the north are highly variable depending upon the location, the availability of suitable construction materials, competitiveness, and contractor experience and confidence. The construction of any lagoon system in the far north is a multi- million dollar capital project.

The operation and maintenance of a lagoon system and the associated sewage collection system is also highly variable. In Grise Fiord, the annual cost for water and sewer was approximately $\$ 2240$ per capita; the sewage portion of this cost was approximately $\$ 670$ per capita.

Lagoon systems are prone to issues associated with the integrity of the berm systems. Performance issues associated with leaking of the berms are becoming significant issues because the facilities are designed for retention with seasonal discharge, and the earth structures are not meeting this requirement. The integrity of the berm systems is associated with the permafrost and other issues that create complex and dynamic geotechnical conditions. Remedial work on a sewage lagoon may cost upward of $1 / 2$ the original cost of the lagoon system [4].

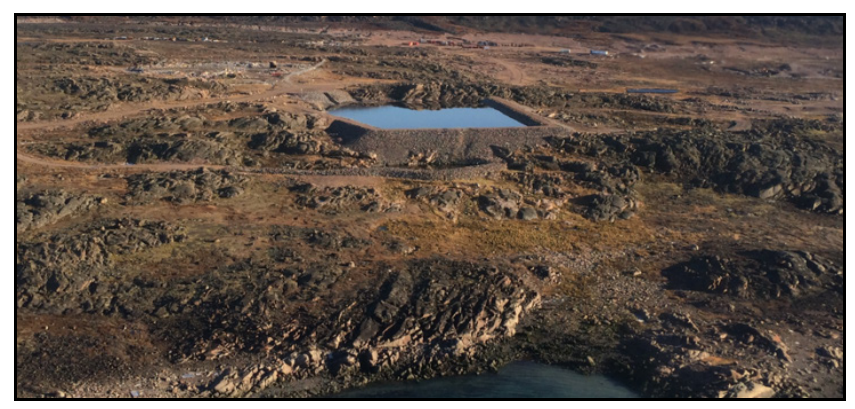

Figure 1. Sewage Lagoon in Kugaaruk, Nunavut in 2016

\section{Nunavut Mechanical Treatment Systems}

Only three communities in Nunavut, namely Rankin Inlet, Pangnirtung, and Iqaluit use mechanical sewage systems. The system in Rankin Inlet is preliminary treatment to remove large solids by screening. The system in Pangnirtung is secondary treatment, which originally used a rotating biological contactor. The system in Iqaluit has preliminary and primary treatment for the removal of solids by screening. Although designs for secondary treatment systems have been completed in Rankin Inlet, construction of the advanced systems has not yet been authorized. Secondary treatment in Iqaluit is currently being designed and a facility may be operational in 2018. All of these existing mechanical systems have had significant operating challenges [5].

\subsection{Rankin Inlet}

The sewage treatment system serving Rankin Inlet is a rotating drum screening plant. Prior to 1996 and the construction of this system, Rankin was discharging into Johnston Cove immediately in front of the community. The discharge into the Cove had limited dispersion, therefore odour and sewage accumulation on the shoreline was a big problem. The screening facility was originally constructed with a 0.3 millimetre screen size, however due to clogging of the screen associated with oil and grease, the screen size was changed to a 1 millimetre screen size.

Raw sewage enters the plant, and accumulates in a surge tank, before being pumped through the rotating screen. The treated sewage is discharged by gravity into Prairie Bay by way of a deep water outfall. A number of modifications were completed to the original installation due to site 
specific issues. The most significant issue was the sewage backup due to the tidal activity, which caused the discharge to back up into the plant during a high tide. This problem was solved with the installation of an air release valve on the outfall pipe.

Another issue was the accumulation of oil and grease on the rotating screen. This was partially addressed with the increase in the screen size, but ultimately a screen cleaning system using a surfactant, in combination with a hot water spray solved the problem. Rankin Inlet has a completed design for a secondary sewage treatment system that is awaiting funding before proceeding.

\subsection{Pangnirtung}

The Pangnirtung facility was originally constructed as an RBC (rotating biological contactor system), but numerous problems with the process equipment prompted the community to adapt the system to a conventional activated sludge process. In 2015 improvements were completed to upgrade the facility once again to an MBR (membrane bioreactor) because the process was severely undersized. The available design information for the previous facility did not clearly identify the rated capacity for the process, but the extremely poor effluent quality and review of the biological process volumes suggested that the system could not handle the required flow and loading conditions.

Raw sewage enters the facility from a truck dump, and passes through a pre-screen. This step removes large material, which is bagged and disposed of at the municipal landfill. From the pretreatment, the sewage enters a compact, high-performance MBR treatment system. New membrane tanks, which had to fit within the existing space to minimize the need to expand the building, were designed with side-opening doors to allow the membrane modules to be installed and removed.

The system was also provides a passive sludge dewatering system using geomembrane filter bags loaded onto a hydraulically activated dump trailer. The completed design repurposed all of the existing building space, and included an addition to the building structure and thermosiphon system to accommodate new process equipment and tanks. The upgrading project cost was $\$ 10,500,000$ including equipment purchase, engineering, construction, start-up, and commissioning services.

\subsection{Iqaluit}

Iqaluit issued a design/build request for proposal (RFP) for secondary treatment in 1997 to replace the existing primary lagoon system, which had been operating since the late 1970's. The terms of reference in the RFP were vague, but an underqualified British Columbia based company responded and captured the project. The main contract was not executed for a considerable time after the work had begun; therefore the work proceeded using rudimentary service contracts.
The contractor took advantage of this situation to maintain a comfortable cash flow without the technical substantiation normally demanded, since Iqaluit did not have an independent owner's representative until well into the project. Unfortunately, Iqaluit expended the entire contract amount of $\$ 7$ million without the substantiation that would later reveal that the facility did not meet code on many items, and the concrete aeration basins were grossly under designed (basin walls displaced upon filling with water), and poorly constructed (basins leaked significantly).

A consultant was retained in 2004 to complete the design for an extensive rehabilitation of the facility. The design was able to incorporate the existing facility, but required two additions to the building; one addition for primary treatment, which was completed in 2006, and another addition for secondary clarifiers, which was not completed due to unavailability of funding. In 2015 , work began to complete the secondary treatment portion of the facility, and MBBR (moving bed bioreactor) technology was selected for this purpose. This process is able to incorporate the original concrete bioreactors cells into the project. A septage receiving system is also being added to the facility. The project is scheduled for completion in 2018, with an estimated capital cost of twenty five-million dollars [6].

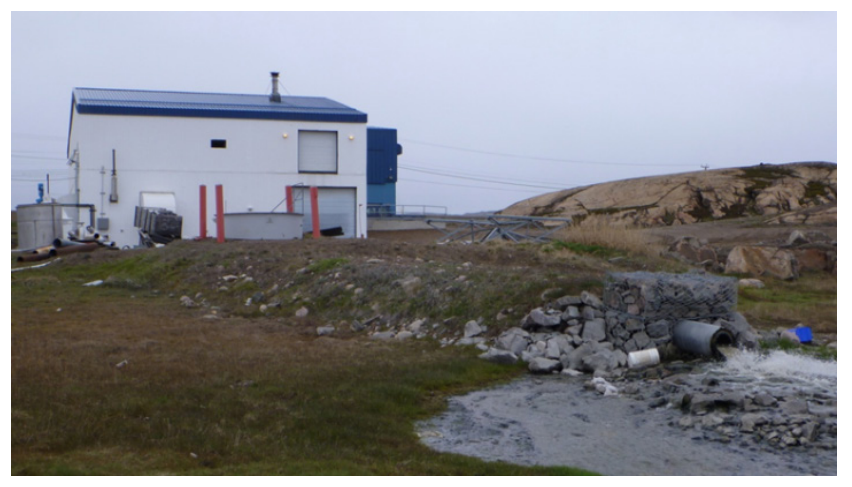

Figure 2. Iqaluit wastewater treatment facility in July, 2013

\section{NWT and Yukon Mechanical Treatment Systems}

\subsection{Fort Simpson, Northwest Territories}

Fort Simpson was under regulatory pressure since the 1980 's to construct a secondary treatment facility, in spite of the fact that the dilution rate in the Mackenzie River (sewage to river flow) is over 300,000 to 1 at the lowest possible river flow. Fort Simpson advanced a project for improvements in the early 1990's with a building, and a treatment process using drum screens with the intent of adding a rotating biological contractor ( $\mathrm{RBC}$ ) process in the future.

Fort Simpson advanced a design/build proposal in 1997 to move to secondary treatment, and Proteus was the selected process with the low capital cost being the 
determining factor in the selection process. The Proteus system abandoned the drum screens in favour of a physical / chemical process. The system was commissioned in 2002, but it has experienced constant performance issues, and as a result, Fort Simpson has been to court several times with the contractor.

Fort Simpson was able to maintain the operation of the Proteus system for almost a decade through their own ingenuity; however, the regulatory demands for process improvements finally prompted the community to advance remedial work. The capital cost of the current remedial work on the WWTP is $\$ 3.7$ million, which has retrofitted the facility with a sequencing batch reactor (SBR) system fitting into an existing building [7].

\subsection{Dawson City, Yukon}

Dawson City was charged under the Fisheries Act in 2002 for discharge of a deleterious substance, and a court order for the construction of wastewater treatment improvements followed. Dawson had been planning to construct an SBR facility, and a design was ready for tendering in 2002, but the annual operation and maintenance estimate of $\$ 600$ thousand halted the project because it was thought to be too expensive.

A new project emerged with the objective of constructing an aerated lagoon just south of the community, and the project advanced to preliminary engineering in 2008 . Unfortunately, this project stopped due to a land use referendum because of the lagoon's proximity to a residential subdivision. The Yukon Government then decided to advance a design/build proposal for a mechanical system, and a design/build contract for $\$ 25$ million was awarded to a contractor in 2009 applying the Vertreat process (deep shaft technology) [8].

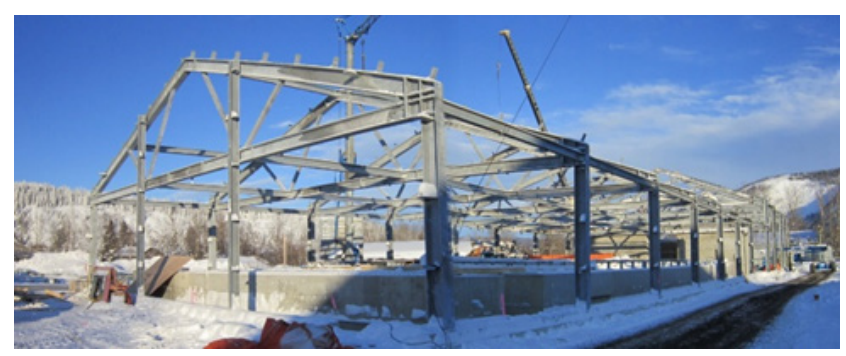

Figure 3. Dawson City wastewater treatment facility during construction in February, 2012

The Vertreat process is a high rate aerobic process which utilizes two, one meter in diameter and 100 metres deep shafts as the aeration basins. The injection of air under high pressure (100 metres) increases the oxygen saturation to 4 times the normal levels and as the activated sludge is saturated with air, it floats in the clarifier. Startup of the facility occurred in August 2012, but the facility, as of 2016, has still not consistently met the performance criteria. The estimated annual operation and maintenance costs for this facility exceed one million dollars, and it is estimated that the remedial work to improve the system performance will cost millions of dollars.

\subsection{Carmacks, Yukon}

The original Carmacks WWTP was commissioned in 1975 , and the facility operated successfully for 35 years. In the 1990's the facility was definitely showing its age, and some "hay wiring" was ongoing to keep it running. A planning study was completed in 2004 to look at various process technologies, particularly a lagoon system, but the topography around Carmacks is steep, so a significant pumping system would be required to convey the sewage to a lagoon site.

A design/build request for proposal was issued in 2005 for a mechanical system, but this process was terminated when the Yukon Government did not approve of the proponent "selected" by the community, which represented the GE Zeeweed membrane technology. The Yukon Government was able to cancel the project for the GE system, and advanced a solution on a piecemeal basis to replace the existing system.

The project proceeded in several stages with the process procurement of an extended aeration activated sludge system as the first stage, followed by the procurement of the building system and the associated equipment. In the end, the overall cost of the facility exceeded the $\$ 6$ million proposal submitted for a design/build project.

The facility has operated reasonably well since it was commissioned in 2009. A detailed inspection of the facility was completed in 2012, and recommended a number of improvements [9].

\section{Factors Influencing Mechanical Systems in the North}

\subsection{Natural Environment}

The natural environment will always have a great influence on the built environment which is associated with any mechanical WWTP in the north. The natural environment influences community access for construction, and operation and maintenance with weather extremes, and highly variable weather at times. This factor prevails whether a community has an all-weather road, or if the year round access is limited to aircraft and relying on the annual sealift for the majority of the community resupply. Since the beginning of modern development over a century ago, the north has been a challenging environment for access, and this has not changed for the most part. A community such as Dawson City still remains a challenge for easy access a 115 years after the Klondike Gold Rush.

The climate segment of the natural environment in northern communities is extremely cold, with an average daily mean temperature of less than zero degrees centigrade for most of the far north. This propensity for cold means that 
all built infrastructure must be designed and constructed for protection against freezing, and in some cases be designed and constructed with provisions for thawing if the facility does freeze.

The construction of any structure in northern communities may be influenced by the presence of permafrost. Permafrost creates a dynamic earth environment that demands particular attention from a design and construction perspective.

The geography segment of the natural environment in northern communities generally creates great distances between the individual communities themselves, and between the communities and major centres further south. In the Yukon, most of the communities have all weather roads so access is simplified, however the road distances are great. In the NWT approximately one half of the communities have all weather road access, and the remainder of the communities have year round access by air, and seasonal access by winter road, or sealift. In Nunavut, none of the communities have all weather road access, and rely solely on year round access by air, and resupply during the sealift period between late July and mid-October.

\subsection{Design and Construction}

The design and construction of a mechanical WWTP in the far north should follow the well established procedures and practices, however these procedures and practices are frequently misunderstood or poorly managed, and the end result are facilities that do not perform. The selection of a WWTP process for the north should be carefully executed because the north is not an appropriate testing realm for new technologies or technologies that do not have a" track record" of performance. An example of this is the selection of a membrane bioreactor in 1997 for the Town of Iqaluit, which was a process technology that was relatively new in southern Canada, and poorly applied to a northern situation.

The consulting resources applied to a WWTP in the north should also have the appropriate northern experience and expertise in all of the technical disciplines associated with a WWTP, which includes wastewater process, structural, geotechnical, heating and ventilation, electrical, and instrumentation and controls. This experience and expertise must be demonstrated as part of the selection process during the request for proposals. An example of the poor selection was the structural engineer's experience associated with the concrete aeration basins for the Iqaluit WWTP; the actual experience of the engineer was associated with concrete residential building foundations in the Okanagan region of British Columbia, and not water retaining structures in a northern environment. This same structural engineer also certified the electrical design drawings for the project.

The contractor experience applied to a WWTP should have the appropriate northern experience. Without this experience, the contractor will ultimately encounter problems at some point in the project. For example, the design build contractors for the Fort Simpson, Dawson City, and Iqaluit WWTP's had never before completed a project of a similar of size, and scope in the far north, and as a result, all of these projects encountered major problems in the project execution.

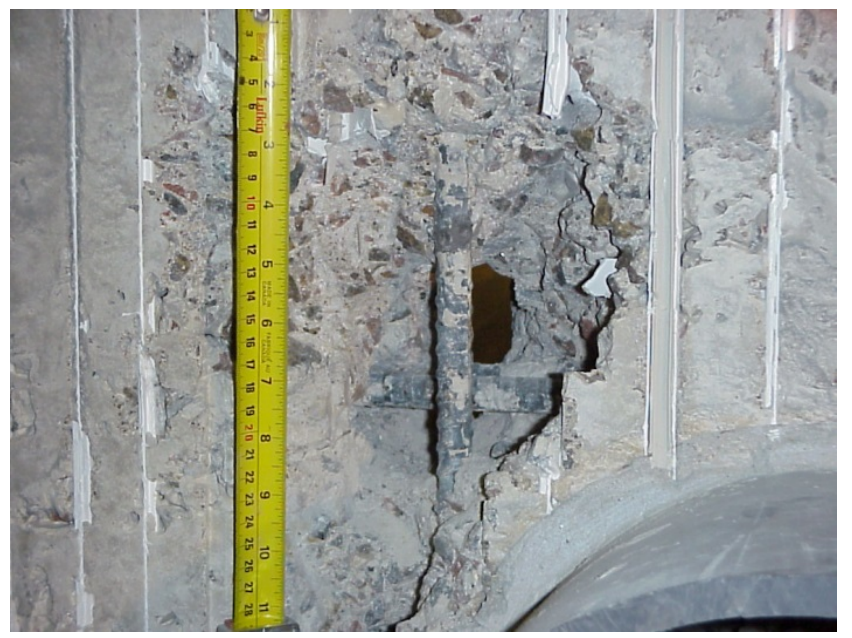

Figure 4. Poor concrete installation in Iqaluit wastewater treatment facility made the facility unusable.

The attention to developing a comprehensive contract associated with the construction of a mechanical WWTP in the far north is an "up front" effort that pays off later on. A poor level of detail was apparent in the request for proposals on the Iqaluit design/build WWTP, which resulted in potentially fewer contractor responses, and greater uncertainty in the project deliverables.

Once a comprehensive contract is prepared, the execution of the contract itself must be completed with the same level of effort and attention to detail as the original contract. In spite of the most comprehensive contract prepared in advance of a project, the poor execution of the contract itself may significantly influence the outcome of a project. For example, the executed contract for Dawson City omitted the submitted tender design drawings by mistake, which allowed the design build contractor additional unwarranted flexibility in the execution of the project. Another example is the Town of Iqaluit, which executed the initial part of the work without a signed contract, using simple service contracts to advance the administration for payment. This ultimately resulted in a WWTP project that expended $\$ 7$ million, and was never completed.

The contract administration must have the resources in place to provide comprehensive contract monitoring, reporting, and responses from beginning to end of a WWTP project in the north. Without this dedicated resource, a project will deviate from the project objectives and may not recover. For example, the Town of Iqaluit did not retain an owner's representative for the 1997 WWTP project until well over a year after the construction began, and ultimately this facility was never completed.

The transportation of materials to a site anywhere in the far north is a logistical challenge in each and every aspect of the process [10]. These challenges include transportation scheduling, and maintaining the material integrity during 
transportation; the material may literally "fall off the wagon" during the transportation to the site. For example, the process tankage for the Carmacks WWTP fell off the truck during transportation to the Yukon, jeopardizing the commissioning of the project.

A particular issue for northern transportation is the need to use ocean transportation for the majority of the materials required for a mechanical WWTP. The far north, in particular, Nunavut does not have road access to any of its communities, and ocean transportation is limited to a window between late July and early October. This transportation limitation influences the entire construction schedule for a mechanical WWTP [11].

The opportunity for the preparation of construction materials on the site in a northern community may offer the potential opportunity for applying features that will improve the performance of the facility, or reduce the cost of construction. However, materials prepared on site, such as structural concrete, are a potential source of problems; for example, poor concrete used in the construction of the water retaining structures on the Dawson City WWTP has jeopardized the design life of the project.

\subsection{Operation and Maintenance}

Operation and maintenance success of facilities in the far north has been suggested to be the ultimate indication of a project's success. Operation and maintenance creates a legacy for community, which may last a generation (25 years), equating to the anticipated design life of a mechanical WWTP.

The operation and maintenance itself, along with the operation and maintenance documentation and the operation and maintenance training, are distinct aspects of the overall operation and maintenance of a WWTP. Operation and maintenance considerations of a facility should begin at the same time as the process design, involving resources with operation and maintenance experience; these considerations should be revisited throughout the design process. If not, a facility may have chronic operational problems from the time of commissioning; for example, the Dawson City facility process is still not successfully operational 4 years after "startup" of the facility in August 2012.

The documentation associated with the operation and maintenance should be a well-defined part of the contract with significant monetary milestones for delivery. Without a monetary or some other incentive, satisfactory documentation may never be delivered on a project. An example of this is the Dawson City operation and maintenance documentation, which remains incomplete 4 years after facility startup.

The training and staffing associated with a mechanical WWTP are aspects of a project that may generally not "enter the picture" until the project is near completion. The challenges of training and staffing are compounded in the north as a result of general human resource issues, and therefore this aspect of a WWTP project should be started at the same time as the design, and be continually advanced throughout the project. Ideally at the time of the project commissioning, the training and staffing should be complete.

\section{Mechanical Systems in Southern Regions of Canada}

In the southern regions of Canada, mechanical WWTP's are used quite frequently when the terrain, location, wastewater regulations, as well as other issues may not accommodate lagoon systems. [12].

A comparable example to the City of Iqaluit facility is the Town of Devon facility in central Alberta. Devon is a town in the province of Alberta, Canada, situated 26 kilometres southwest of Edmonton, the provincial capital, and located along the banks of the North Saskatchewan River.

From a climate perspective, Devon is considerably warmer than communities in the north, with an average annual temperature of $2.6^{\circ} \mathrm{C}$. A warmer climate means that heating costs are considerably lower with regard to the amount of heating energy used and the cost of the heating energy. Protection against freezing is still an issue, but the freeze protection does not require the same level of redundancy and resiliency that facilities in the far north require.

The design of the structure is considerably easier for the Devon facility because the design elements are not influenced by ground conditions that may include permafrost that would be encountered as part of the development of a northern facility. Other elements of the design including heating and ventilation would not need to facilitate the extreme temperature variations, and robust features.

The constructability of the facility is be considerably easier because of year round access for delivery of materials, access by road instead of water in the far north, and access to a large skilled workforce.

The operation and maintenance of the facility requires the same level of effort as a facility in the far north, however the available resources for the day to day operation and maintenance generally have more extensive training, and more WWTP experience. Access to resources for operation and maintenance outside the normal range of activities is considerably easier, as well, with the resources available within driving distance.

The cost of operation is a major legacy for any mechanical WWTP. The anticipated operation and maintenance cost for the WWTP in Iqaluit is anticipated to be $\$ 1$ million, whereas the cost in Devon is anticipated to be $\$ 500,000$ [13]. The majority of the additional costs are associated with energy consumption.

\section{Conclusions}

In spite of the challenges associated with mechanical 
WWTP systems in the north, there have been a few successes. The most significant success story has been the mechanical WWTP in the community of Pangnirtung, Nunavut, where the interest and efforts of the local operator have maintained the successful operation of the facility.

Although mechanical WWTP's have experienced many challenges in their application in the far north, they do offer the opportunity to reduce the influence of the natural environment. In considering a mechanical WWTP, the multitude of factors associated with the design, construction, operation and maintenance of these systems in the far north must be fully considered. The experienced technical disciplines must also be fully engaged for the duration of the project.

The consideration of operation and maintenance of a WWTP, and the engagement of the local human resources to be responsible for the operation and maintenance, cannot be over emphasized. A WWTP is a community legacy that will last a generation, and significantly impact the human and financial resources of the community.

The synopsis of mechanical WWTP's systems presented in this paper from across the far north is complete in the facilities it has presented (6 in total), but is not complete in the presentation on each facility. This documentation will provide information to hopefully to mitigate many of the challenges associated with mechanical wastewater systems for future facilities. However, each and every project in the Canadian north is unique, so ultimately there is no "recipe" for success, however with the communication of project experiences, the potential list of things that can go wrong when a project is underway may be greatly reduced.

\section{REFERENCES}

[1] Northwest Territories Water Board, Guidelines for the Discharge of Municipal Wastewater in the NWT, 1992.

[2] Johnson, K. and Wilson, A., Sewage Treatment Systems in Camps and Communities of the Northwest Territories, CSCE Annual Conference, 1999.

[3] Johnson, K., and Cucheran, J., Performance Evaluation of Sewage Lagoon in Iqaluit, Nunavut, International Cold Regions Specialty Conference, 1994.

[4] Stantec Consulting Ltd., Kugaaruk Sewage Lagoon Study, 2016.

[5] Northern Territories Water and Waste Association Journal, Rocks, Snow and Wastewater Treatment in Pangnirtung, Nunavut, 2005.

[6] Stantec Consulting Ltd., Iqaluit WWTP Upgrade / Expansion Feasibility Study, 2015.

[7] Stantec Consulting Ltd., Fort Simpson WWTP Facility Upgrades Report, 2012.

[8] Stantec Consulting Ltd., Dawson City Wastewater Treatment Plant Performance, 2016.

[9] Associated Engineering Ltd., Carmacks, Yukon, WWTP Engineering Assessment, 2012.

[10] Johnson, K., Project Delivery in the Far North - Then and Now, Western Canada Water Magazine, Winter, 2011.

[11] Johnson, K., Municipal Engineering North of 60. Canadian Civil Engineer, 1992

[12] Partanen, S., Mechanical Wastewater Treatment in the Canadian Arctic, 2014.

[13] Stantec Consulting Ltd., Devon Preliminary Engineering Report, 2014. 